\title{
Screening and follow-up for paroxysmal nocturnal hemoglobinuria
}

\section{Vodolazkaia A, Schuermans W, Rummens J-L, Hendrickx A, Maes B, Claeys R, Peeters V.}

Jessa Ziekenhuis Hasselt

\section{Introduction}

PNH or Paroxysmal Nocturnal Hemoglobinuria is a rare hematopoietic stem cell disorder that is often suspected in a patient presenting with non-immune hemolytic anemia associated with pancytopenia or venous thrombosis. Screening of appropriate patients and accurate diagnosis of $\mathrm{PNH}$ are important.

Recently published paper (Mercier et al., 2017) investigated the clinical indications for $\mathrm{PNH}$ testing in the University hospital setting.

In this study we investigated the reasons for $\mathrm{PNH}$ analysis request and the results of the PNH tests in the non-University hospital setting, by using the methodology of Mercier et al.

\section{Methods}

We retrospectively reviewed flow cytometric PNH tests performed between February 2011 and February 2017. We determined the reason for $\mathrm{PNH}$ analysis request, based on the clinical and laboratory data.

We divided all requests into the following reasons for testing: hemolytic anemia (HA), aplastic anemia, cytopenia other than $\mathrm{HA}$, trombosis, MDS, follow-up (FU), no clinical data available.

\section{Results}

A total of 266 flow cytometric $\mathrm{PNH}$ tests (corresponding to 171 patients) were performed.

Of these 171 patients, 16 unique $\mathrm{PNH}$ positive patients were identified, of which 8 had two or more PNH FU tests. 14 from the 16 unique $\mathrm{PNH}$-positive patients were tested for $\mathrm{PNH}$ for the first time.

Table 1 shows the reasons for $\mathrm{PNH}$ testing in the 266 samples and in 90 $\mathrm{PNH}$-positive samples, respectively.

Cytopenia (other than HA) was the most common reason for testing in all samples.

\begin{tabular}{|l|c|c|}
\hline Reasons for testing & $\begin{array}{c}\text { All samples } \\
\mathrm{N}(\%)\end{array}$ & $\begin{array}{c}\text { PNH-positive samples } \\
\mathrm{N}(\%)\end{array}$ \\
\hline Hemolytic anemia & $29(11)$ & $4(4,4)$ \\
\hline Cytopenia other than HA & $98(36,8)$ & $4(4,4)$ \\
\hline Aplastic anemia & $6(2,3)$ & $4(4,4)$ \\
\hline Trombosis & $14(5,3)$ & $1(1,1)$ \\
\hline MDS & $2(0,75)$ & 0 \\
\hline Follow Up & $76(28,6)$ & $76(84,4)$ \\
\hline No clinical data & $41(15,4)$ & $1(1,1)$ \\
\hline
\end{tabular}

Table 1. Reasons for $\mathrm{PNH}$ testing.

$86 \%$ of all samples and $96,6 \%$ of $\mathrm{PNH}-$ positive samples were requested by a hematologist (Table 2).

\begin{tabular}{|l|c|c|}
\hline Specialisation & $\begin{array}{c}\text { All samples } \\
\mathrm{N}(\%)\end{array}$ & $\begin{array}{c}\text { PNH-positive samples } \\
\mathrm{N}(\%)\end{array}$ \\
\hline Heamatology & $228(86)$ & $87(96,7)$ \\
\hline Oncology & $6(2,3)$ & $2(2,3)$ \\
\hline Gastro-Enterology & $10(3,8)$ & 0 \\
\hline Cardiology & $4(1,5)$ & 0 \\
\hline Nephrology & $4(1,5)$ & 0 \\
\hline Internal Medicine & $2(0,75)$ & $1(1,1)$ \\
\hline Geriatrics & $3(1,1)$ & 0 \\
\hline Emergency & $2(0,75)$ & 0 \\
\hline Other & $7(2,6)$ & 0 \\
\hline
\end{tabular}

Table 2. Request for $\mathrm{PNH}$ testing per specialisation.
The highest probability of finding a $\mathrm{PNH}$ clone was founded in patients suffering from aplastic anemia (fig.1). Our findings in a nonuniversity hospital setting is in agreement with the previous data in the university hospital setting of Mercier et al., (2017).

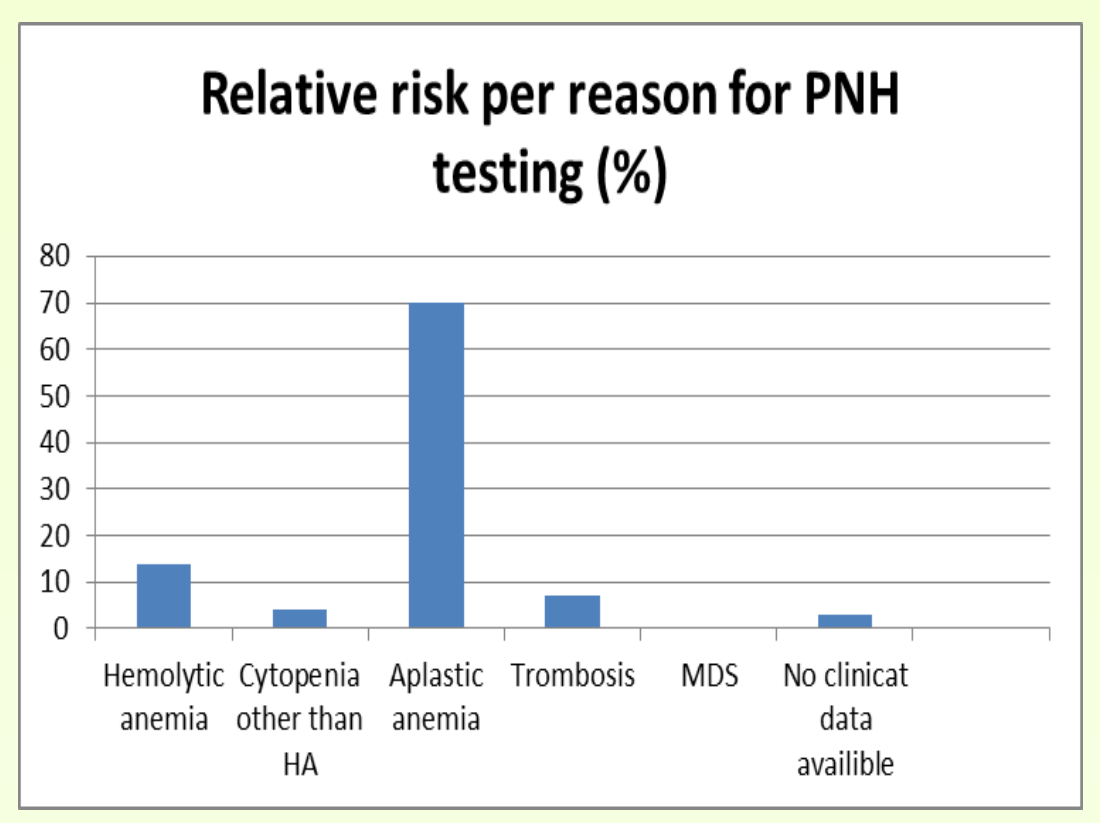

Figure 1. Probability to find a $\mathrm{PNH}$ clone

\section{Conclusion}

Cytopenia (other than $\mathrm{HA}$ ) was the most common reason for testing in all samples.

The highest probability of finding a $\mathrm{PNH}$ clon was in patients tested because of aplastic anemia.

$96,7 \%$ of $\mathrm{PNH}$ - positive samples were requested by a hematologist.

\section{References}

1. Mercier T, Devos T, Mukovnikova M, Boeckx N. Diagnosing nocturnal paroxysmal hemoglobinuria: a singlecenter 4-year experience. Int J Lab Hematol. 2017 39:329-336

2. Borowitz MJ, Craig FE, Digiuseppe JA, Illingworth AJ, Rosse W, Sutherland DR, Wittwer CT, Richards SJ; Clinical Cytometry Society. Guidelines for the diagnosis and monitoring of paroxysmal nocturnal hemoglobinuria and related disorders by flow cytometry. Cytometry $\mathrm{B}$ Clin Cytom. 2010 Jul;78(4):211-30 